\title{
SCIENCE, POLITICS, AND LAND MANAGEMENT
}

\author{
Jack Ward Thomas and James Burchfield
}

A $s$ the intensity of the debates concerning land use assessments and planning inexorably increase, and the resultant allocation of increasingly scarce natural resources produces winners and losers, there is a parallel and increasing demand for the application of "good science" in the process. This demand is heard-and equally loudly-from those on each side of increasingly polarized issues related to public land management issues. In other words, the participation of scientists and the application of science are being increasingly demanded, in principal at least, and are increasingly confused in application.

The situation results, we believe, from confusion in the minds of the public and politicians as to what scientists are and science is. This relatively new reliance on science and scientists is the latest attempt to produce a sure-fire approach to making land management decisions that will be universally accepted by all parties "with a dog in the fight" and by the courts. These conflicts, after all, beg resolution, which seems increasingly unlikely, and what and who better to provide "final and irrefutable truth" than science and scientists?

Such blind faith in the application of "good science" as a panacea to gridlock is unjustified, and it presents several shortcomings that must be recognized and addressed before science and scientists can play as useful a role as possible in land-use planning and management processes. It is well to understand that the application of scientifically derived information and insights in management almost always requires a considerable degree of synthesis of such information from a myriad of sources that commonly span several disciplines. Large-scale efforts at synthesis often require both intradisciplinary and interdisciplinary team efforts. Understandably enough, intradisciplinary teams work better together and more efficiently than interdisciplinary teams.

The issue of bias has been widely acknowledged among the scientists themselves, it is only the observers of science that wish to uphold the myth of pure objectivity.

However, it is well to understand that scientists, by and large, see the world through lenses tinted and ground to differing calibration by virtue of their disciplinary backgrounds. Further, scientists are not free of bias. The scientific method is designed to help overcome investigator bias-but such always exists and the possibility, even probability, of bias creeping into analysis must be recognized and addressed.

Scientists must make choices about the variables that are worthy of concern and measure, and these decisions are commonly sorted by worldviews that are fundamentally human. Microbiologist Robert Pollack (1999) proposes that scientists respond to an "inner voice," an unconscious upwelling of val- ues that drives creativity and motivates discovery. Lele and Norgaard (1996), a biologist and an economist respectively, observe that the nature of scientific thinking requires scientists to adopt broad images of reality to formulate analytical constructs, forcing a priori decisions on relevant factors, their interrelationships, and their boundaries. The issue of bias has been widely acknowledged among the scientists themselves, it is only the observers of science that wish to uphold the myth of pure objectivity.

Information pertinent to problem solution is commonly produced in a number of disciplines. This means that any appropriate approach to the use of science and scientists in planning or assessment requires cross-disciplinary efforts. Equally important, cross-disciplinary work requires a more complex, iterative peer review process, such that multiple specialists have occasion to examine and critique interactive effects. As of this moment, there are only a handful of such efforts that have produced results that have received even faint and conditional praise (Johnson et al., 1999). The good news is that these experiences have provided information useful in succeeding efforts-adaptive management in action. But even then there are still significant adjustments to be made following each iteration of experience.

These experiences have been sobering in that it has become clear that such efforts require the attention of highly trained and appropriately experienced scientists. Therefore, such efforts are expensive. With rare exceptions, appropriate personnel have had to be recruited from the ranks of agency research personnel or from counterparts in academia to fill key roles, including that of leadership. At present, most management personnel are not adequately trained nor experienced to carry out such highly technical leadership roles, nor do they have resources to employ consultants to lead such efforts and operate satisfactorily across disciplinary lines.

It is simply past time for federal and state land management agencies to seriously consider alternatives for assuring the existence of an adequately trained and experienced staff of scientists to carry out the increasing demands of science assess-

Clearly, the agencies must either recruit doctoral level specialists, "up-train" personnel (which we would recommend), or both, to carry out these increasingly demanding and difficult tasks. This, of course, opens up the necessity to pay these persons at the levels necessary to attract and retain qualified personnel. That means paying such specialists as much, or likely more, than their superiors in the bureaucratic hierarchy. This is not an easy thing to achieve in paramilitary governmental organizations-but it is very likely essential. 
ment and evaluation. At present, agency research staffs are still repeatedly raided for qualified personnel to address one high priority job after another. This crisis-oriented response cannot be tolerated much longer. There is a dramatic need for these very same scientists to go to work on research questions that had surfaced in completed or ongoing assessments and evaluations.

Clearly, the agencies must either recruit doctoral level specialists, "up-train" personnel (which we would recommend), or both, to carry out these increasingly demanding and difficult tasks. This, of course, opens up the necessity to pay these persons at the levels necessary to attract and retain qualified personnel. That means paying such specialists as much, or likely more, than their superiors in the bureaucratic hierarchy. This is not an easy thing to achieve in paramilitary governmental organizations-but it is very likely essential.

These land management and regulatory agencies have "crossed the Rubicon" in terms of firmly establishing precedents for high quality assessment and analyses. There is, in our opinion, no going back. And, the new planning rules proposed for the national forest system assure that the bar for performance has been permanently raised. The agencies must hire, or train, the personnel that can deliver in a sustainable fashion at that enhanced level of performance. It is no longer, or should not be, possible or credible to pretend that these recurrent demands are merely aberrant crises that will likely not occur again. Let us face the fact that crises demanding assessment and evaluation of alternatives of very high quality are now routine in the federal land management business.

..too many scientists assume that the public and
politicians understand what science is and scientists
are.

That recognition should be coupled with full understanding that the increasingly litigious nature of the world of natural resources management-particularly on the public's lands-requires an increasingly demanding adherence to legally prescribed, intricate processes, including the appropriate and thorough consideration and application of science by qualified scientists. The rise of the "conflict industry," wherein advocates on the environmental and user-group sides bring the big guns of litigation, propaganda, fund raising, demonstrations, and opinions of various experts immediately to bear on any action or process undertaken by management agencies, assures challenge to many, if not most, assessments or proposals.

Commonly, at some point, each side in the conflict will produce experts and scientists to lay out alternative assessments of available information. They will argue that whatever scheme or assessment so far produced is "fatally flawed" (a favorite term in these spitting matches) in the synthesis or application of available information or in terms of perfect adherence to prescribed processes.

Such disagreements should not, of necessity, paint scientists involved in conflict in a bad light. Scientists are carefully conditioned over a prolonged period of education to challenge existing knowledge (hypotheses) about how the world works. And any synthesis of information within a discipline, or between disciplines, is subject to alternative interpretation.
Certainly, differences of opinion among scientists will occur over what pieces of information from the overall mass of information are pertinent to the questions at hand.

The chances for significant differences of opinion to arise increase rapidly when synthesis involves a multi-disciplinary effort. Scientists accept that-even more, they thrive on the "game." However, too many scientists assume that the public and politicians understand what science is and scientists are. Too frequently this includes a belief, or a leap of faith, that there is only one scientific "truth" that would emerge if the process of assessment and evaluation are appropriately conducted, using "qualified scientists" and confining considerations to "good science." We now understand that this belief is unfounded and, as Sheila Jasanoff (1990) observes, competing claims of truth in regulatory science lead us to a pragmatic "negotiated science" in which information and the public interest are carefully weighed in the balance.

The next highly naïve assumption that many politicians and the general public make is that when the "right" science, produced and certified by scientists, is on the table, there will be a decision made as to appropriate natural resource management that all concerned will consider acceptable. For, after all, such a decision is surely "scientifically sound." As the most sensitive nerve in the human body has been said to run from one's pocket book directly to the heart, such acceptance of a decision contrary to one's welfare is not likely. Decisions antithetical to the interests of any group of players in the natural resources management game will not be considered acceptable-regardless whether or not the decisions were based on "good science."

The only natural resources management decisions that will remain operative over any appreciable time frame will satisfy four factors. Kennedy and Thomas (1995) described this basic relationship in a Venn diagram (Figure 1a). Such management decisions are:

\section{1. within legal bounds}

2. within ecological capability

3. economically feasible

4. socially/politically acceptable

Whether or not the decision being made lies within the acceptable decision space accorded by the overlap of these factors can be determined in one of two ways. Initial assessment can evaluate compliance with the following factors. The legality of the proposed actions is evaluated by legal counsel. Ecological capability can be judged by an experienced interdisciplinary team with appropriate credentials. Economic ramifications are judged by economists. And, social acceptability and impacts are projected by social/political scientists. Obviously, the amount of decision space available to managers can be altered by manipulations of the assumptions related to each of these variables. This can be visualized as increased flexibility in any portion of the system pushing the circles toward the center and increasing decision space (Figure 1b). More constraints can be visualized as pulling the circles away from the center and decreasing decision space (Figure 1c). Obviously, the decision space is largely constrained by the most intractable variable. This allows managers to direct attention to what wildlife biologists refer to as Liebig's Law of the Minimum, i.e., the overall result will be limited by the 


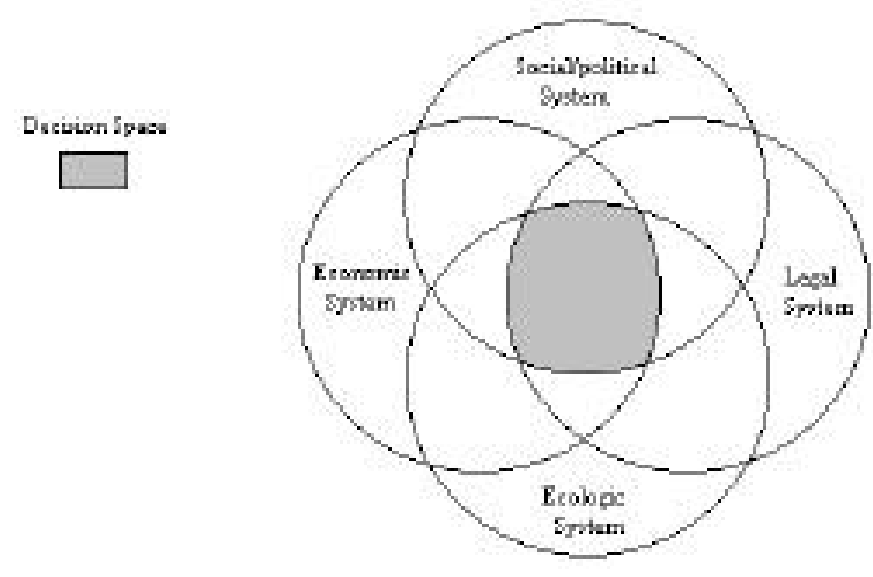

Fig. 1a. The interactions of various systems bearing on decision space.

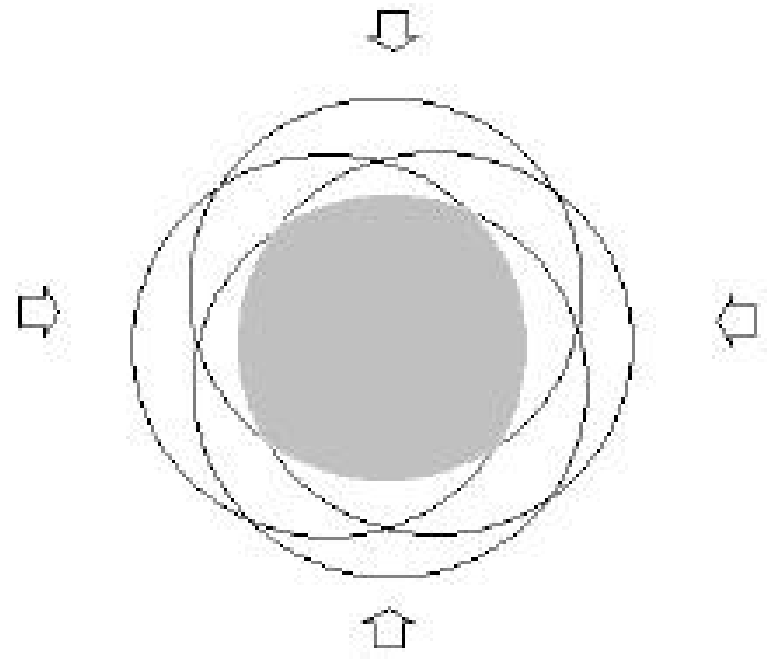

Fig. 1b. "Loosening" made in one or more of the decision variables pushes the systems inward, producing increases in both risk and management flexibility (decision space).

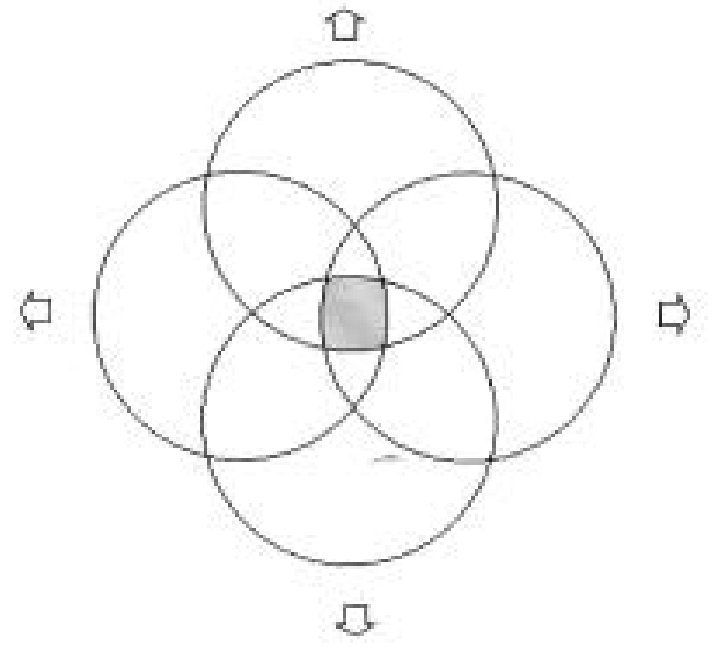

Fig. 1c. "Tightening” is one or more decision variables pulls the sys tem apart and reduces both risk and management flexibility (deci sion space).. most constraining variable(s).

That in turn introduces the need for risk assessment, i.e., the likelihood of achieving projected outcomes in the alternatives under consideration. Risk assessments are constructed considering the variations in the individual factors by alternatives, and then considering the interactions of the four (or however many) operating systems. Such manipulations can produce many iterations of outcomes for consideration of decisionmakers, and from which final alternatives for consideration are derived. It will always emerge that the greater the risk assumed, the greater the manager's decision space-and conversely, the most constraints accepted the less the risk.

As a general rule, managers in multiple-use land management agencies, given their mission, will opt for a bit more risk over a shorter time frame with a mid-course correction with the intent of enlarging decision space. Regulatory agency managers, given their mandates, will opt for little or no risk over a longer time frame. That will, in turn, dramatically reduce decision space. If there are threatened or endangered species involved, for example, the concerns of the regulatory agency will be the trump card in the gaming of risk.

The planning and assessment efforts are further complicated by the almost continuous emergence of new informationtechnical, political, economic, legal - that bears on land management decisions, even those of long-standing. The reaction to such a tattoo of new information creates pressure for a constant adjustment in plan execution and even revision of plans through amendment.

This new information derives from several sources. Included in this array are new laws (and the anticipated interactions with extant laws), results of court cases, new research findings, and management experience, including results from monitoring efforts - both formal and informal-leading to adjustments in a process of adaptive management.

This ebb and flow of information and subsequent adjustments in management activities including planning can be viewed as a reassuring corrective factor to the status quo, since it forces attention on those issues related to important public concerns. As we have acknowledged earlier, information is frequently amassed based on what may be interesting to scientists, but not necessarily relevant to the political questions at hand. And as political scientists such as A. D. Socolow (1987) have argued, analyses are often not about what is important, but what is easy to measure. As long as we concentrate on what may be attractive to scientists and readily measurable, we may be discounting other relevant contextual factors that affect policy concerns. Politics brings us back to the root of the issue.

This new information feeds back to guide changes in management action in a process of what has been called adaptive management. Conceptually at least, if such changes are anticipated and welcomed as clarifying agents, management changes will occur routinely through plan revision without the undue costs and culture shock associated with a routine resistance to inevitable alterations.

That is the theory. In reality, the current system of decision making and plan alteration-the process requirements-are simply too onerous, inflexible, and expensive to encourage, or even allow, timely adjustments. Oddly, a lack of plan adjustments made in a timely manner frequently leads to a manage- 


\section{Applied research is carried out to address identified gaps in knowledge or understanding necessary to address critical management prob- lems.}

ment "train wreck." In the end these train wrecks prove even more expensive in time, money, and consternation for the public and politicians. The old saying of "pay me now or pay me later" has a certain ring of truth in such situations.

Therefore, while science and scientists have a definite and growing role to play in natural resources management, they are only one of many players in the assessment and planning game. What is the appropriate role for scientists in this regard?

The traditional role of conducting research to provide the underpinning for informed management is, traditionally at least, the scientist's designated role in these affairs. Such research activities include basic research to provide knowledge for the sake of knowledge itself, but which in often surprising ways provide key understandings essential to clarification of a larger management picture. Cause and effect relationships are revealed, as well as unexpected intervening variables.

Applied research is carried out to address identified gaps in knowledge or understanding necessary to address critical management problems. More recently, interpretation of research findings in a form understandable to practitioners and interested publics is increasingly recognized as a significant

Clearly and most appropriately, scientists are but one set of players in the natural resources planning and assessment game.

role for scientists.

These research activities set the stage for the critical next step of bringing scientists and science appropriately to bear in land management. To that end scientists have been employed more and more frequently in the synthesis of scientifically derived information for application in assessment, planning, and management. Such synthesis ordinarily crosses disciplinary boundaries, and most commonly requires multi-disciplinary teams to accomplish satisfactorily.

It should be clearly realized that synthesis of applicable technical information and its application in assessments, planning, and evaluation is not "science" per se. Rather it is synthesis, assessment, planning, and evaluation done by scientists, and, the elevated educational level of the participants notwithstanding, is no more or less than that.

Scientists should not make decisions about the appropriate course of management action. That is the duty and prerogative of appointed decision-makers and elected officials. However, scientists can and do serve a valuable role in evaluating whether alternatives under consideration are compatible with the extant state of knowledge.

It is most definitely not the role of scientists to dictate the appropriate levels of risk in decision making. Scientists, however, should have responsibility to see that risks of alternative management actions are described as accurately and completely as possible. Clearly and most appropriately, scientists are but one set of players in the natural resources planning and assessment game. But now that scientists have been so heavily involved in several high-profile assessment and planning efforts, it should be apparent that the rules of the game have changed. Application of an equivalent level of scientific expertise will be expected in future efforts.

If scientists play their appropriate role, it can be accurately said that resultant management decisions are science based. And it should be equally clear that management decisions, inevitably and appropriately in our view, will be value driven.

Science and scientists, playing a well-defined role in the assessment and planning process, can enhance natural resource management decisions by providing insights, information, risk assessments, and evaluated alternatives for consideration of appropriate decision makers. Scientists must guard against being misused, even inadvertently, in assessment and planning processes. And it should be the responsibility of scientists to educate others, with specific attention to managers, the public, and elected officials, as to their proper role in land management activities.

\section{Citations}

Jasanoff, S. 1990. The fifth branch: Science advisors as policymakers. Cambridge: Harvard University Press.

Johnson, K.N., F. Swanson, M. Herring, and S. Greene. 1999. Bioregional assessments - science at the crossroads of management and policy. Island Press, Washington, D.C., and Covelo, Calif.

Lele, S. and R. Norgaard. 1996. Sustainability and the scientists' burden. Conservation Biology. Vol. 19, No. 2. pp. 354-365

Pollack, R. 1999. The missing moment: How the unconscious shapes modern science. Boston: Houghton Mifflin.

Sokolow, A. D. 1987. Small governments as newcomers to American federalism. Publius: The Journal of Federalism. 17(3): 113.

The authors are, respectively, Boone and Crockett Professor of Wildlife Conservation and Chief Emeritus, U.S. Forest Service and Director, Bolle Institute, The university of Montana. 